\title{
A Macrolevel Examination of County-Level Risk Factors for Underage Drinking Prevention: Intervention Opportunities to Protect Youth in the State of Georgia
}

\author{
Karen E. O'Quin, ${ }^{1}$ Sheryl M. Strasser, ${ }^{2}$ and Monica H. Swahn' \\ ${ }^{1}$ Department of Community Health and Health Behavior, School of Public Health and Health Professions, University at Buffalo, \\ 320 Kimball Hall, Buffalo, NY 14214, USA \\ ${ }^{2}$ Institute of Public Health, Georgia State University, P.O. Box 3995, Atlanta, GA 30302, USA
}

Correspondence should be addressed to Karen E. O’Quin, karenoquin@gmail.com

Received 30 June 2011; Revised 5 December 2011; Accepted 17 December 2011

Academic Editor: Masha Gartstein

Copyright (C) 2011 Karen E. O'Quin et al. This is an open access article distributed under the Creative Commons Attribution License, which permits unrestricted use, distribution, and reproduction in any medium, provided the original work is properly cited.

\begin{abstract}
Introduction. Underage drinking can have profoundly negative impacts on childhood development. This study compares 4 categories of known underage drinking risk factors with alcohol consumption. The social indicators in these categories will be compared in the 10 most-at-risk (MAR) counties and the 10 least-at-risk (LAR) counties identified in Georgia. Methods. Independent 2-tailed $t$-tests were conducted to compare group means among MAR and LAR counties for all identified risk factors. Results. Significant differences were observed in all factors included in the poverty and alcohol outlet density categories. Discussion. The findings underscore the importance of better understanding youth drinking, poverty, and alcohol outlet density. However, our findings, supported by previous individual and aggregated level research, support strategies for researchers and policy makers to more proactively respond to poverty-stricken and high-density alcohol outlet indicators. The current ecological evaluation of underage drinking risk assessed on a macrolevel offers insights into the demographic features, social structures, and cultural patterns of counties that potentially predispose youth to greater health risks specifically associated with underage drinking.
\end{abstract}

\section{Background}

Underage drinking can have a profound impact on childhood development. Research shows that early alcohol use initiation increases risk for heavy alcohol use, alcohol dependence, and alcohol-related harm to others and self $[1,2]$. Early underage drinking is also linked to peer and dating violence [3], and other negative outcomes such as problems in school, weapon carrying, or recent marijuana use [4]. Furthermore, alcohol consumption is a significant risk factor for unsafe sexual behaviors, unintentional injuries, physical and sexual assaults, various types of illegal activities, and suicide $[3,5-8]$. With all the known negative consequences of early alcohol use, adolescents in the United States [US] still use alcohol more than any other substance, including tobacco and marijuana. By the age of 15, nearly one half of American youth have consumed an entire alcoholic beverage, and 18-20-year olds have a higher prevalence of alcohol dependency than any other age group [8].

Despite the volume of research on underage drinking, there is surprisingly very little information about the range of influences at the macrolevel that may contribute to, or exacerbate risk for, underage drinking. In the state of Georgia, a relatively new initiative to assess social indicators across counties has permitted new and innovative analyses of factors that may impact health, including underage drinking. This study is based on the findings of the 2006 Governor's Cooperative Agreement State Incentive Planning and Development Grant released by the Social Indicator Study to Assess Substance Use Prevention Needs at the State and County Levels in Georgia (SIS). One unique feature of the SIS is that it examines multiple sociodemographic and behavior variables on the county level and ranks each county on 29 risk constructs and an overall composite score [9]. The state of Georgia has 
159 counties (second to Texas for the most counties within a US state). Georgia counties provide an appealing level of public health analysis because surveillance tends to occur on the county level [10]. The SIS was initiated as a means to inform policy makers, service providers, and public health professionals.

The project presented here focuses on four specific categories identified within the literature: drinking consequences, urbanicity, poverty, and alcohol outlet density. JonesWebb and colleagues defined drinking consequences as "concrete problems that arise in different areas of an individual's life because of drinking" such as citations for driving under the influence (DUI), alcohol-related arrests, hospitalizations, and treatment admissions [11]. Fourteen percent of adolescents between 17 and 21 presenting in emergency rooms tested positive for alcohol use [12]. As much as $29 \%$ of young drivers ages 15-20 that had been killed in motor vehicle accidents had been drinking alcohol [13]. Heavy episodic drinking, drinking in cars, and individual expectations about the negative consequences of DUI all influence an adolescent's decision to drive drunk or ride with someone under the influence [14-16]. Research also suggests that chronically low rates of underage drinking and DUI arrests may lead to decreased awareness of DUI as a drinking consequence among young people [13, 17].

The relationship between urban/rural living and alcohol consumption has been frequently reported in the literature, especially among adults, and with often contradictory results $[18,19]$. Youth in rural environments consume more alcohol than their urban counterparts [20-23]. A few studies, however, found either no difference between urban and rural youth or that urban youth have higher rates of alcohol consumption $[24,25]$.

The association between poverty and alcohol consumption in adults has also been documented, yet few studies attempt to ascertain the relationship between poverty and alcohol consumption in underage drinkers. Poverty, lower household income, and neighborhood deprivations have all been found to be associated with problem drinking, regardless of race/ethnicity or gender [26-29]. In contrast to previously mentioned adult studies, findings from New Zealand show that higher levels of income were associated with increased frequency of underage drinking, but not intensity. Although New Zealand has some similarities to the US, it is difficult to determine the comparability of these results with the US [30].

A final category of risk considers alcohol outlet density related to consumption. Among adults, alcohol outlet density has been found to be associated with increased self-reported drinking and driving [31], automobile crashes [32], and overall alcohol consumption [33]. Another study found that outlet density showed no significant individual-level effects and suggested that neighborhood-level associations were indicative of the clustering of individuals with alcohol problems rather than outlet density influence [34].

Literature reporting the effects of alcohol outlet density on underage drinking is limited. Among the few published studies, varying methodologies, alcohol consumption constructs, and study samples utilized yield extremely limited results. Alcohol outlet density has been positively correlated with decreased parental monitoring, which in turn has been positively correlated with increased youth alcohol consumption [35]. Higher densities of outlets have been associated with both driving under the influence and riding with an intoxicated driver [36], and colleges located in neighborhoods with more alcohol outlets experience more drinking- and driving-related problems [37]. In terms of examining youth drinking in relationship to alcohol outlet density, one study utilizing GIS software found no significant correlations; however the study authors disclosed that only suburban areas were examined which traditionally have restricted access to commercial resources and a lower prevalence of alcohol use in general [38].

Based on these earlier findings, this study sought to examine the potential association between drinking consequences, urbanicity, poverty, and alcohol outlet density on underage alcohol consumption in the 10 healthiest counties and the 10 least healthy counties in the state of Georgia to determine strategies for prevention.

\section{Methods}

This study examined state and federally collected data from the SIS. Selected study indicators were obtained from standard administrative and reporting databases generated by the source agencies [9].

Ten Georgia counties identified as the most-at-risk (MAR) and the 10 counties that had been identified as least-at-risk (LAR) counties (based on overall SIS ranking) on 15 different variables representing the categories of drinking consequences, urbanicity, poverty, and alcohol outlet density were compared in this study. Variables are presented in Table 1. The risk construct composite scores reflect alcohol-related problems-the higher standardized values, the more vulnerable, more negative consequences of alcohol reported. Due to the fact that there are 159 counties in the state, the top 10 counties have unusually high clusters of risk and therefore, are optimal for intensive intervention/programming opportunity.

Analyses were conducted on the 10 MAR (ranked 150159), and the 10 LAR (ranked 1-10). The number of counties in each group was chosen arbitrarily, but with the intent of capturing an accurate sample of at-risk counties versus not-at-risk counties. Two-tailed, independent $t$-test and bivariate correlations were conducted for comparison of the means of two groups for the indicators from all 4 categories. All analyses were performed in SPSS version 17.

\section{Results}

Comparisons of drinking consequences were not found to be significantly different across high- and low-risk counties. Similarly, the $t$-test scores for urbanicity did not indicate that population density or percent of the population living in urban areas was significantly different between the high-risk and low-risk counties.

The $t$-test for the percent of the total population BPL indicated that the mean differences between the top 10 and 
TABLE 1: Risk variables and definitions within each category.

\begin{tabular}{|c|c|}
\hline Category & Variable \\
\hline \multirow{4}{*}{$\begin{array}{l}\text { Drinking } \\
\text { consequences }\end{array}$} & Juvenile arrest rate for liquor violations \\
\hline & $\begin{array}{l}\text { Percent of alcohol-related vehicle crashes; } \\
\text { drivers 10-17 }\end{array}$ \\
\hline & $\begin{array}{l}\text { Percent of alcohol-related vehicle crashes; } \\
\text { drivers } 18-21\end{array}$ \\
\hline & Juvenile alcohol treatment admission rate \\
\hline \multirow{2}{*}{ Urbanicity } & Population density \\
\hline & Percent of population living in urban areas \\
\hline \multirow{8}{*}{ Poverty } & Percent of residential properties vacant \\
\hline & $\begin{array}{l}\text { Percent of children living below the poverty } \\
\text { level (BPL) }\end{array}$ \\
\hline & Percent of total population living BPL \\
\hline & Unemployment rate \\
\hline & $\begin{array}{l}\text { Percent of population receiving temporary } \\
\text { assistance to needy families [TANF] }\end{array}$ \\
\hline & Percent of population receiving food stamps \\
\hline & $\begin{array}{l}\text { Percent of students receiving } \\
\text { free/reduced-price lunches }\end{array}$ \\
\hline & Percent of single-parent households \\
\hline $\begin{array}{l}\text { Alcohol outlet } \\
\text { density }\end{array}$ & $\begin{array}{l}\text { Number of alcohol licenses per } 1,000 \\
\text { persons }\end{array}$ \\
\hline
\end{tabular}

TABLE 2: Poverty group statistics.

\begin{tabular}{|c|c|c|c|c|}
\hline \multicolumn{5}{|c|}{ Poverty group statistics (10 MAR \& 10 LAR) } \\
\hline Indicator & Group & Mean & $\begin{array}{l}\text { Standard } \\
\text { deviation }\end{array}$ & $\begin{array}{c}\text { Standard } \\
\text { error }\end{array}$ \\
\hline \multirow{2}{*}{$\%$ of children below FPL } & MAR & 8.94 & 1.59 & 0.50 \\
\hline & LAR & 2.07 & .77 & 0.24 \\
\hline \multirow{2}{*}{$\begin{array}{l}\% \text { of total population } \\
\text { below FPL }\end{array}$} & MAR & 22.67 & 3.76 & 1.19 \\
\hline & LAR & 6.12 & 1.89 & 0.60 \\
\hline \multirow{2}{*}{$\begin{array}{l}\% \text { of residential properties } \\
\text { vacant }\end{array}$} & MAR & 13.01 & 1.34 & 0.42 \\
\hline & LAR & 6.09 & 3.14 & 0.99 \\
\hline \multirow{2}{*}{ Unemployment rate } & MAR & 5.46 & 1.08 & 0.34 \\
\hline & LAR & 3.11 & .389 & 0.12 \\
\hline \multirow{2}{*}{$\begin{array}{l}\% \text { of population receiving } \\
\text { TANF }\end{array}$} & MAR & 2.92 & 0.54 & 0.17 \\
\hline & LAR & 0.50 & 0.26 & 0.08 \\
\hline \multirow{2}{*}{$\begin{array}{l}\% \text { of population receiving } \\
\text { food stamps }\end{array}$} & MAR & 15.00 & 1.77 & 0.56 \\
\hline & LAR & 2.94 & 1.47 & 0.47 \\
\hline \multirow{2}{*}{$\begin{array}{l}\% \text { of students receiving free } \\
\text { or reduced-price lunches }\end{array}$} & MAR & 69.57 & 6.52 & 2.06 \\
\hline & LAR & 23.88 & 8.79 & 2.78 \\
\hline \multirow{2}{*}{$\begin{array}{l}\% \text { of single-parent } \\
\text { households }\end{array}$} & MAR & 34.68 & 6.11 & 1.93 \\
\hline & LAR & 16.05 & 3.55 & 1.12 \\
\hline
\end{tabular}

bottom 10 counties were highly significant $[t=-12.446]$ $(P<.001) . t$-Tests for the percentage of children BPL $[t=$ $-12.287](P=.001)$, the percent of vacant residential properties $[t=-6.408](P<.001)$, unemployment rate $[t=$ $-6.472](P=.000)$, percent of the population receiving TANF $[t=-12.748](P<.001)$, percent of the population receiving food stamps $[t=16.573](P<.001)$, and the
TABLE 3: Alcohol outlook group statistics.

\begin{tabular}{lccc}
\hline \multicolumn{4}{c}{ Alcohol outlet density group statistics (10 MAR \& 10 LAR) } \\
\hline \multicolumn{4}{c}{ Number of alcohol licenses per 1,000 people } \\
Group & Mean & Standard deviation & Standard error \\
\hline MAR & 2.93 & 0.43 & 0.14 \\
LAR & 1.26 & 0.50 & 0.16 \\
\hline
\end{tabular}

percent of children receiving free/reduced lunches $[t=$ -13.207] $(P<.001)$ were all highly significant. Finally, the percent of single-parent households showed significance $[t=-8.333](P<.001)$. Correlations among all poverty indicators were strongly significant. Poverty group statistics can be seen in Table 2 , and the results of the significant $t$-test are presented in Table 4.

The $t$-test for the number of alcohol licenses per 1,000 people was also significant $[t=-7.969](P<.001)$. Furthermore, alcohol outlet density was highly correlated with: the number of single-parent households (.787), the number of students receiving free/reduced lunch (.878), vacant residential properties (.841), the percentage of children BPL (.868), the percent of the total population BPL (.879), the unemployment rate $(.821)$, the percent of the population receiving TANF (.843), and the percent of the population receiving food stamps $(.884)$. The above correlations were all significant at the $(P<.001)$. Urbanicity group statistics can be seen in Table 3 , and the results of the significant $t$-test are presented in Table 4 .

\section{Discussion}

The findings from this study, conducted at the macrolevel, demonstrate that indicators pertaining to poverty and alcohol outlet density appear to be most strongly related to underage alcohol use and that drinking consequences and urbanicity appear less important. Although the significance of underage drinking consequence should not be ignored, the results of this analysis suggest that other indicators are more important.

Similarly, urbanicity was also not important in these analyses, which is inconsistent with previous research. Although a majority of studies indicate that underage drinking is a larger problem in rural areas [18-23], there is a small contingent that maintains that there is either no difference or that urban areas exhibit higher rates of alcohol use [22, 24, 25]. A large part of this controversy could be attributed to nonstandardized underage drinking and urbanicity measures.

In terms of poverty, all individual indicators showed significant differences between the MAR and the LAR groups. The indicators were also highly correlated with one another. Stimpson and colleagues theorized that "a mechanism linking neighborhood deprivation to mortality and morbidity maybe the influence contextual forces have on shaping individual health risk behaviors [29]." Their study identified significant associations between neighbor deprivation, income levels, and excessive alcohol assumption [29]. Chuang and colleagues found that living in lower-socioeconomic status 
TABLE 4: Significant $t$-tests.

Significant $t$-test of social determinants from the 10 MAR and LAR counties

\begin{tabular}{|c|c|c|c|c|c|c|c|c|c|}
\hline \multirow{2}{*}{\multicolumn{2}{|c|}{ Indicator }} & & \multicolumn{2}{|c|}{ Levine's test } & \multicolumn{5}{|c|}{$t$-test for equality of means } \\
\hline & & & $F$ & Sig. & $t$ & Df & Sig. (2-tailed) & Mean diff & SE \\
\hline \multirow{16}{*}{ Poverty } & \multirow{2}{*}{$\%$ of children BPL } & EVA & 4.348 & .052 & -12.29 & 18 & .000 & -6.87 & .56 \\
\hline & & EVNA & & & -12.29 & 13.010 & .000 & -6.87 & .56 \\
\hline & \multirow{2}{*}{$\%$ of total population BPL } & EVA & 7.993 & .011 & -12.45 & 18 & .000 & $-1.66 \mathrm{E} 1$ & 1.33 \\
\hline & & EVNA & & & -12.45 & 13.285 & .000 & $-1.66 \mathrm{E} 1$ & 1.33 \\
\hline & \multirow{2}{*}{$\%$ residential properties vacant } & EVA & 1.932 & .181 & -6.41 & 18 & .000 & -6.92 & 1.08 \\
\hline & & EVNA & & & -6.41 & 12.182 & .000 & -6.92 & 1.08 \\
\hline & \multirow{2}{*}{ Unemployment rate } & EVA & 10.169 & .005 & -6.47 & 18 & .000 & -2.35 & .36 \\
\hline & & EVNA & & & -6.47 & 11.304 & .000 & -2.35 & .36 \\
\hline & \multirow{2}{*}{$\%$ of population receiving TANF } & EVA & 10.766 & .004 & -12.75 & 18 & .000 & -2.42 & .19 \\
\hline & & EVNA & & & -12.75 & 13.058 & .000 & -2.42 & .19 \\
\hline & \multirow{2}{*}{$\%$ of population receiving food stamps } & EVA & .001 & .973 & -16.57 & 18 & .000 & $-1.21 \mathrm{E} 1$ & .73 \\
\hline & & EVNA & & & -16.57 & 17.446 & .000 & $-1.21 \mathrm{E} 1$ & .73 \\
\hline & \multirow{2}{*}{$\%$ of students receiving free/reduced lunches } & EVA & 2.608 & .124 & -13.21 & 18 & .000 & $-4.57 \mathrm{E} 1$ & 3.46 \\
\hline & & EVNA & & & -13.21 & 16.611 & .000 & $-4.57 \mathrm{E} 1$ & 3.46 \\
\hline & \multirow{2}{*}{$\%$ of single-parent households } & EVA & 2.641 & .121 & -8.33 & 18 & .000 & $-1.86 \mathrm{E} 1$ & 2.24 \\
\hline & & EVNA & & & -8.33 & 14.467 & .000 & $-1.86 \mathrm{E} 1$ & 2.24 \\
\hline \multirow{2}{*}{$\begin{array}{l}\text { Alcohol } \\
\text { outlet }\end{array}$} & \multirow{2}{*}{ Number of alcohol licenses/1,000 people } & EVA & .279 & .604 & -7.97 & 18 & .000 & -1.66 & .21 \\
\hline & & EVNA & .088 & .771 & -7.97 & 17.640 & .000 & -1.66 & .21 \\
\hline
\end{tabular}

neighborhoods was associated with greater amounts of peer drinking which was consequently associated with greater amounts of youth alcohol consumption [39].

Of the 4 categories examined in this study, the link between poverty and underage drinking has been least studied from a developmental or public health perspective. Poverty, however, seems to have a highly significant connection to underage drinking. This should be highly relevant to researchers, academics, and policymakers concerned with child development and health. The strong associations between the correlates provide a clear contextual landscape of the communities in which children would be most at risk. The cluster of associations supports the life course perspective, which posits the cumulative build-up of social determinants of health from birth through death. In turn, research to quantify this relationship further could inform intervention development which could drive policies that target underage drinking risks in low-socioeconomic status neighborhoods.

Finally, the $t$-test conducted to examine differences in alcohol outlet density was also significant. Alcohol outlet density significantly correlated with all poverty indicators. This has a potentially confounding effect since it is impossible to determine if high outlet densities actually affect the risk of underage drinking, or if high outlet densities are a product of poverty. It is possible that it is a combination of the two. Widespread social issues, such as underage drinking, are complex, which makes it extremely difficult to flush out individual causal factors. Whatever the case, the scant literature attempted to analyze the relationship between youth drinking and alcohol outlet density, and this is an area that merits continued research.

\section{Limitations}

This study and approach have many important limitations that are outlined below and should be considered when interpreting the findings. The construct of "at-risk" versus "notat-risk" counties was derived from the SIS methodology, whereby all individual indicators were standardized (given an equal weight). In reality, some indicators may be more strongly associated with underage alcohol consumption than others but since that was not a criterion for the development of the index, it was not considered. Moreover, the analyses were based on secondary data. As such, our analyses were limited because the intent of the SIS was not to specifically compare high- and low-risk counties on the factors associated with underage drinking. With that specific goal in mind, the data could have been collected, analyzed, and presented differently. Most specifically, our limitations pertain to the underage drinking consequences analyzed in the study because they largely depend on record keeping and surveillance systems that may or may not be available across counties depending on resources, size of population, and priorities. Moreover, measures like alcohol testing in car crashes is also more likely to be performed when a fatality has occurred and as such may not be equally reflected across counties depending on distribution of highways and other roadway factors. Additionally, other measures may have similar concerns and also reflect availability and levels of police enforcement efforts, or treatment availability which likely vary across counties and jurisdiction based on a number of factors that were not assessed in the SIS. We also relied on a broad age category (ages 10 to 17 ) that may not adequately reflect 
variation within this age group in particularly for driving. However the FBI systematically aggregates the data this way and while it is less useful for driving particularly, it is what we have available. Moreover, many of the social risk factor constructs were originally identified from individual-level data, and directly analogous measures at the county-level may not exist. Research regarding correlations between social indicators and actual amounts of alcohol use within a community is limited. This study only examined the risk of underage drinking in Georgia and therefore may not be illustrative or generalizable to other states [9]. Despite these limitations, the findings from these preliminary analyses can help inform future projects and add to the limited research on these factors and underage drinking at the aggregate level.

\section{Conclusions}

Underage drinking is a complex issue that spans demographic categories and has many interrelated, contributing factors. If there is to truly be an understanding of the scope and consequence of underage drinking in the US, a more accurate, efficient underage drinking surveillance system is needed with information available at the county level. Underage drinking research that integrates assessment of urbanicity, poverty, and alcohol outlet density risk is an important priority for future research. Research in these areas can inform targeted intervention and prevention efforts including enactment of new policies. Standardization of the urban/rural continuum in research would help clarify the relationship between urbanicity and underage drinking. Because differences were observed between the MAR and the LAR counties in all of the poverty alcohol outlet density indicators, researchers and policy makers should focus on these two areas specifically when designing further research and prevention policies.

This study is important because underage drinking can strongly impact childhood development. Examining countylevel data is an innovative approach that complements individual-level research and can aid program planners and professionals from diverse backgrounds gain a better understanding of where risk factors cluster within states. Clearly, despite the many policy-level initiatives and resources directed towards underage drinking, it is apparent that new approaches and strategies are needed to make a significant reduction in the prevalence of underage drinking and its dire consequences. This needs to be an important priority for the safe and healthy development of our youth.

\section{References}

[1] R. Hingson, T. Heeren, and M. Winter, "Age at drinking onset and alcohol dependence," Archives of Pediatrics and Adolescent Medicine, vol. 160, no. 7, pp. 739-746, 2006.

[2] R. Hingson and Z. Wenxing, "Age of drinking onset, alcohol use disorders, frequent heavy drinking, and unintentionally injuring oneself and others after drinking," Pediatrics, vol. 123, no. 6, pp. 1477-1484, 2009.

[3] M. Swahn, R. Bossarte, and E. Sullivent, "Victimization and perpetration among high-risk, seventh-grade adolescents age of alcohol use initiation, suicidal behavior, and peer and dating violence," Pediatrics, vol. 121, no. 2, pp. 297-305, 2008.

[4] N. Peleg-Oren, G. Saint-Jean, G. Cardenas, H. Tammara, and C. Pierre, "Drinking alcohol before age 13 and negative outcomes in late adolescence," Alcoholism: Clinical and Experimental Research, vol. 33, no. 11, pp. 1966-1972, 2009.

[5] M. Swahn, T. Simon, B. Hammig, and J. Guerrero, "Alcoholconsumption behaviors and risk for physical fighting and injuries among adolescent drinkers," Addictive Behaviors, vol. 29, no. 5, pp. 959-963, 2004.

[6] R. Hingson, T. Heeren, M. Winter, and H. Wechsler, "Magnitude of alcohol-related mortality and morbidity among U.S. college students ages 18-24: changes from 1998 to 2001," Annual Review of Public Health, vol. 26, pp. 259-279, 2005.

[7] A. Stueve and L. N. O'Donnell, "Early alcohol initiation and subsequent sexual and alcohol risk behaviors among urban youth," American Journal of Public Health, vol. 95, no. 5, pp. 887-893, 2005.

[8] US Department of Health and Human Services, The Surgeon General's Call to Action To Prevent and Reduce Underage Drinking, U.S. Department of Health and Human Services, Office of the Surgeon General, 2007.

[9] B. Weimer and P. Graham, "Governor's cooperative agreement state incentive planning and development grant: social indicator study to assess substance use prevention needs at the state and county levels in georgia," Tech. Rep., Georgia Department of Human Resources, RTI International, NC, USA, 2006.

[10] E. Jackson, A Brief History of Georgia Counties, Georgia Info, 2009.

[11] R. Jones-Webb, C. Hsiao, P. Hannan, and R. Caetano, "Predictors of increases in alcohol-related problems among black and white adults: results from the 1984 and 1992 National Alcohol Surveys," American Journal of Drug and Alcohol Abuse, vol. 23, no. 2, pp. 281-299, 1997.

[12] S. Meropol, R. Moscati, K. Lillis, S. Ballow, and D. Janicke, "Alcohol-related injuries among adolescents in the emergency department," Annals of Emergency Medicine, vol. 26, no. 2, pp. 180-186, 1995.

[13] Substance Abuse and Mental Health Services Administration, The NSDUH Report: Driving Under the Influence in Young Persons, SAMHSA, 2004.

[14] J. Grube and R. Voas, "Predicting underage drinking and driving behaviors," Addiction, vol. 91, no. 12, pp. 1843-1857, 1996.

[15] J. Muilenburg, W. Johnson, S. Usdan, L. Annang, and D. Clayton, "Prevalence of impaired driving behaviors in a diverse, rural, southern middle school," Accident Analysis and Prevention, vol. 39, no. 6, pp. 1080-1087, 2007.

[16] S. Walker, E. Waiters, J. Grube, and M. Chen, "Young people driving after drinking and riding with drinking drivers: drinking locations- what do they tell us?" Traffic Injury Prevention, vol. 6, no. 3, pp. 212-218, 2005.

[17] A. Wagenaar and M. Wolfson, "Enforcement of the legal minimum drinking age in the United States," Journal of Public Health Policy, vol. 15, no. 1, pp. 37-53, 1994.

[18] E. Jackson, M. Doescher, and G. Hart, "Problem drinking: rural and urban trends in America, 1995/1997 to 2003," Preventive Medicine, vol. 43, no. 2, pp. 122-124, 2006.

[19] T. Borders and B. Booth, "Rural, suburban, and urban variations in alcohol consumption in the United States," Journal of Rural Health, vol. 23, no. 4, pp. 314-321, 2007.

[20] J. Gfroerer, S. Larson, and J. Colliver, "Drug use patterns and trends in rural communities," Journal of Rural Health, vol. 23, supplement 1, pp. 10-15, 2007. 
[21] S. Kogan, C. Berkel, Y. Chen, G. Brody, and V. Murry, "Metro status and African-American adolescents' risk for substance use," Journal of Adolescent Health, vol. 38, no. 4, pp. 454-457, 2006.

[22] D. Lambert, J. Gale, and D. Hartley, "Substance abuse by youth and young adults in rural America," Journal of Rural Health, vol. 24, no. 3, pp. 221-228, 2008.

[23] C. Schultz and C. Neighbors, "Perceived norms and alcohol consumption: differences between college students from rural and urban high schools," Journal of American College Health, vol. 56, no. 3, pp. 261-265, 2007.

[24] P. Fletcher and K. Skinner, "Do drinking practices at university differ among students coming from urban and rural centers? A preliminary examination for knowledge, attitudes, and beliefs," College Student Journal, vol. 40, no. 2, pp. 332-334, 2006.

[25] F. Gibbons, R. Reimer, M. Gerrard et al., "Rural-urban differences in substance use among African-American adolescents," Journal of Rural Health, vol. 23, supplement 1, pp. 22-28, 2007.

[26] Centers for Disease Control and Prevention, "Sociodemographic difference in binge drinking among adults-14 states, 2004," Morbidity and Mortality Weekly Report, vol. 58, pp. 301304, 2009.

[27] K. Mossakowski, "Is the duration of poverty and unemployment a risk factor for heavy drinking?" Social Science and Medicine, vol. 67, no. 6, pp. 947-955, 2008.

[28] N. Mulia, Y. Ye, and S. Zemore, "Social disadvantage, stress, and alcohol use among black, hispanic, and white Americans: findings from the 2005 U.S. National Alcohol Survey," Journal of Studies on Alcohol and Drugs, vol. 69, no. 6, pp. 824-833, 2008.

[29] J. Stimpson, H. Ju, M. Raji, and K. Eschbach, "Neighborhood deprivation and health risk behaviors in NHANES III," American Journal of Health Behavior, vol. 31, no. 2, pp. 215-222, 2007.

[30] S. Casswell, M. Pledger, and R. Hooper, "Socioeconomic status and drinking patterns in young adults," Addiction, vol. 98, no. 5, pp. 601-610, 2003.

[31] P. Gruenewald, F. Johnson, and A. Treno, "Outlets, drinking and driving: a multilevel analysis of availability," Journal of Studies on Alcohol, vol. 63, no. 4, pp. 460-468, 2002.

[32] K. Kelleher, S. Pope, R. Kirby, and V. Rickert, "Alcohol availability and motor vehicle fatalities," Journal of Adolescent Health, vol. 19, no. 5, pp. 325-330, 1996.

[33] P. Gruenewald and W. Ponicki, "The relationship of outlet densities and alcohol sales to alcohol-related traffic crashes," Alcoholism: Clinical and Experimental Research, vol. 17, pp. 3847, 1993.

[34] R. Scribner, D. Cohen, and W. Fisher, "Evidence of a structural effect for alcohol outlet density: a multilevel analysis," Alcoholism: Clinical and Experimental Research, vol. 24, no. 2, pp. 188-195, 2000.

[35] B. Freisthler, H. Byrnes, and P. Gruenewald, "Alcohol outlet density, parental monitoring, and adolescent deviance: a multilevel analysis," Children and Youth Services Review, vol. 31, no. 3, pp. 325-330, 2009.

[36] A. Treno, J. Grube, and S. Martin, "Alcohol availability as a predictor of youth drinking and driving: a hierarchical analysis of survey and archival data," Alcoholism: Clinical and Experimental Research, vol. 27, no. 5, pp. 835-840, 2003.

[37] H. Wechsler, J. Lee, and J. Hall, "Secondhand effects of student alcohol use reported by neighbors of colleges: the role of alcohol outlets," Social Science and Medicine, vol. 55, no. 3, pp. 425-435, 2002.
[38] K. Pasch, M. Hearst, M. Nelson, A. Forsyth, and L. Lytle, "Alcohol outlets and youth alcohol use: exposure in suburban areas," Health and Place, vol. 15, no. 2, pp. 642-646, 2009.

[39] Y. Chuang, S. Ennett, K. Bauman, and V. Foshee, "Neighborhood influences on adolescent cigarette and alcohol use: mediating effects through parent and peer behaviors," Journal of Health and Social Behavior, vol. 46, no. 2, pp. 187-204, 2005. 


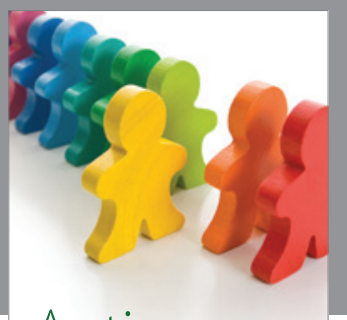

Autism

Research and Treatment
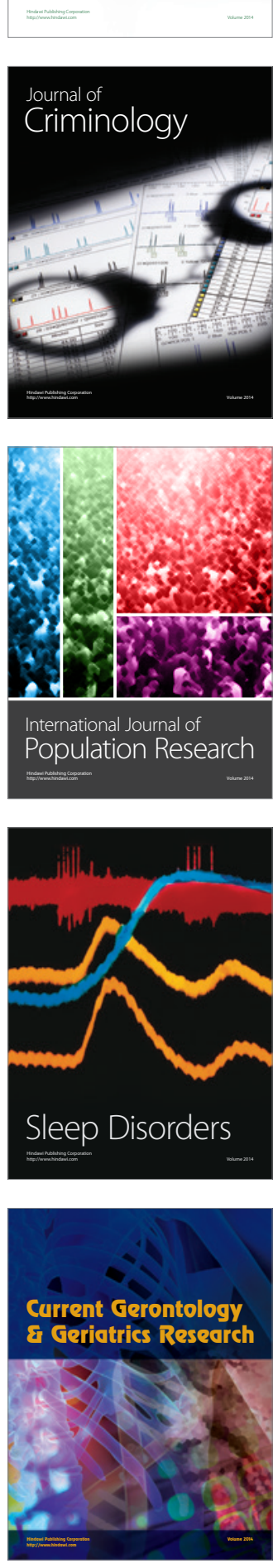
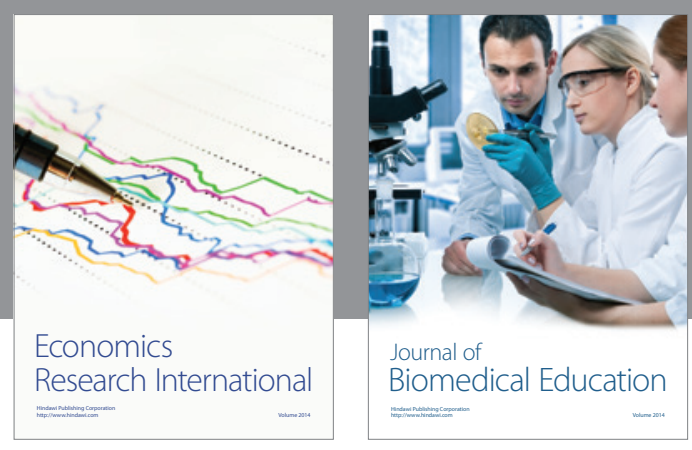

Journal of

Biomedical Education

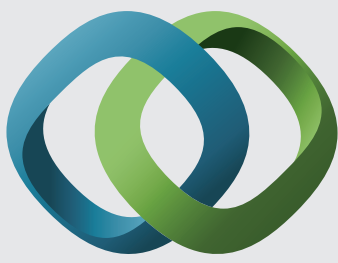

\section{Hindawi}

Submit your manuscripts at

http://www.hindawi.com
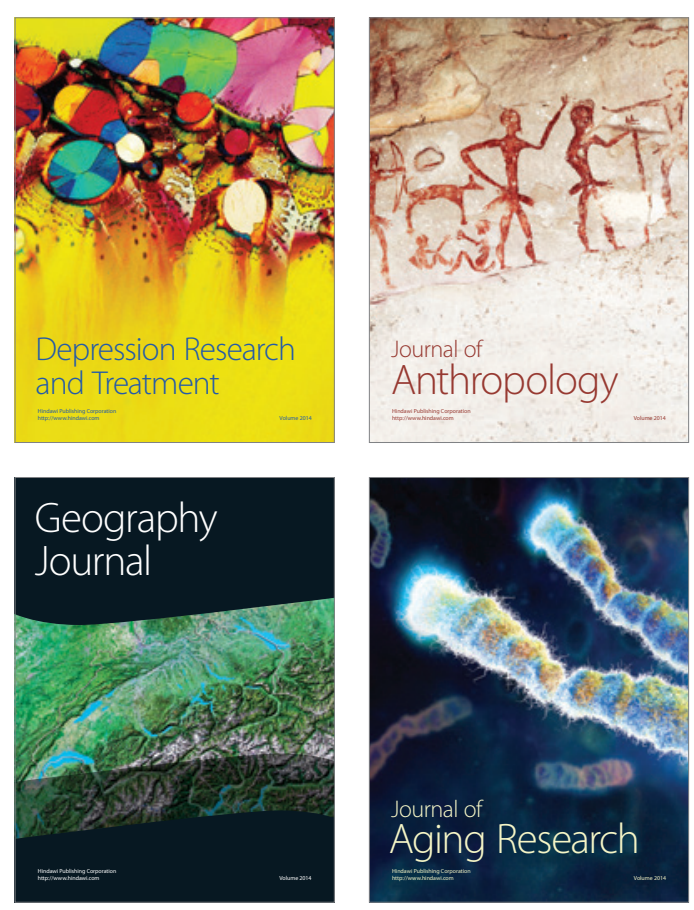

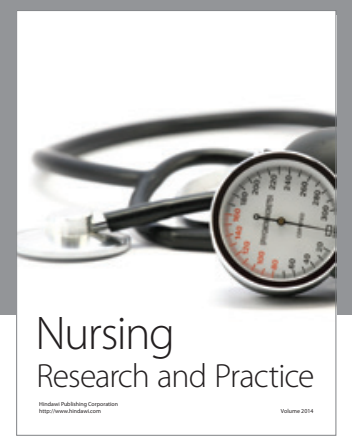

Nursing

Research and Practice

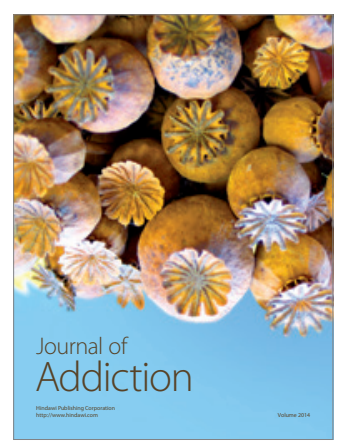

Child Development

Research

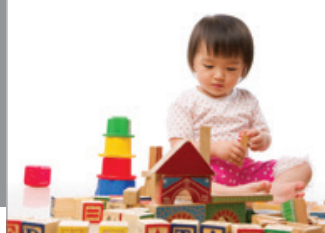

迥
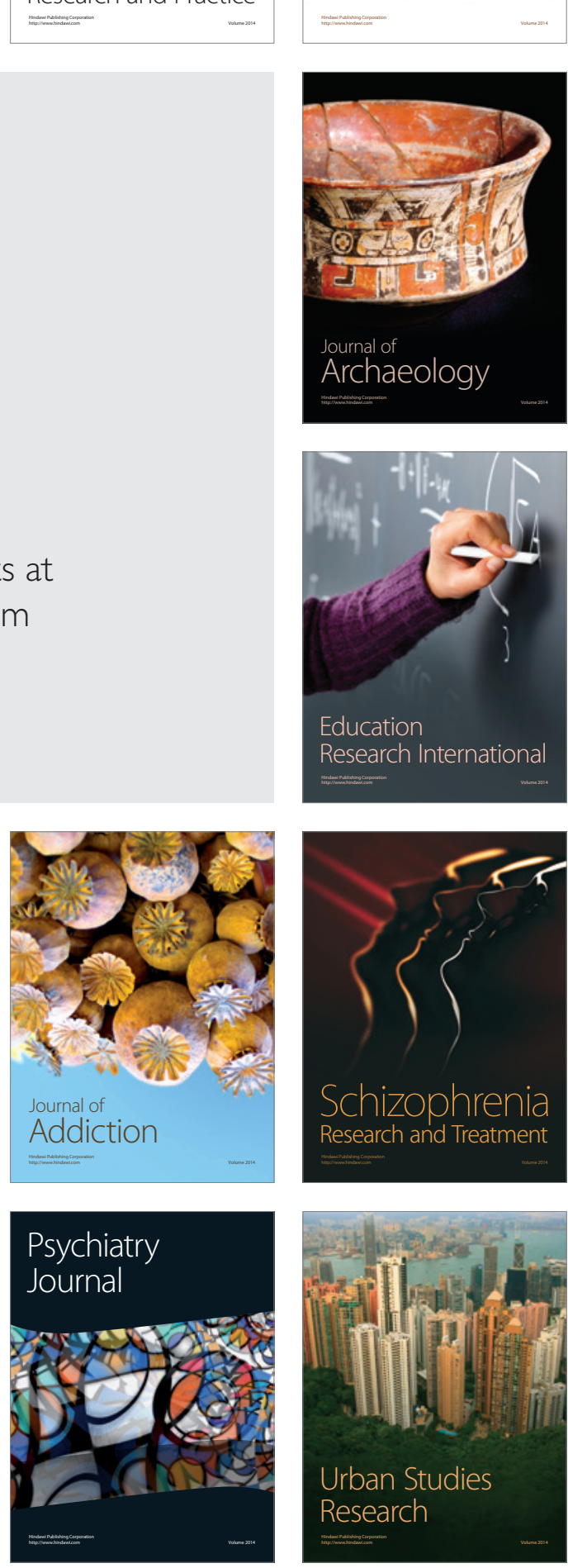